\title{
A method for increasing electroporation competency of Gram-negative clinical isolates by Polymyxin B nonapeptide
}

Jilong Qin ( $\sim$ Jilong.qin@qut.edu.au )

Queensland University of Technology

\section{Yaoqin Hong}

Queensland University of Technology

Karthik Pullela

The University of Queensland

Renato Morona

University of Adelaide

lan R. Henderson

The University of Queensland

Makrina Totsika ( $\square$ Makrina.totsika@qut.edu.au )

Queensland University of Technology

\section{Research Article}

Keywords: PMBN, Electroporation, Transformation, Lambda Red mutagenesis, TIS

Posted Date: January 12th, 2022

DOI: https://doi.org/10.21203/rs.3.rs-1248341/v1

License: (9) (i) This work is licensed under a Creative Commons Attribution 4.0 International License. Read Full License 


\section{Abstract}

The study of clinically relevant bacterial pathogens relies on molecular and genetic approaches. However, the generally low transformation frequency among natural isolates poses technical hurdles to widely applying common methods in molecular biology, including transformation of large constructs, chromosomal genetic manipulation, and dense mutant library construction. Here we demonstrate that culturing clinical isolates in the presence of polymyxin B nonapeptide (PMBN) improves their transformation frequency via electroporation by up to 100-fold in a dose-dependent and reversible manner. The effect was observed for PMBN-binding uropathogenic Escherichia coli (UPEC) and Salmonella enterica strains but not naturally polymyxin resistant Proteus mirabilis. Using our PMBN electroporation method we show efficient delivery of large plasmid constructs into UPEC, which otherwise failed using a conventional electroporation protocol. Moreover, we show a 5 -fold increase in the yield of engineered mutant colonies obtained in $S$. enterica with the widely used lambda-Red recombineering method, when cells are cultured in the presence of PMBN. Lastly, we demonstrate that PMBN treatment can enhance the delivery of DNA-transposase complexes into UPEC and increase transposon mutant yield by 8 -fold when constructing Transposon Insertion Sequencing (TIS) libraries. Therefore, PMBN can be used as a powerful electropermeabilisation adjuvant to aid the delivery of DNA and DNA-protein complexes into clinically important bacteria.

\section{Introduction}

Delivery of foreign DNA into Gram-negative bacteria is a routine procedure in molecular microbiology and is essential for gene cloning, mutagenesis, and construction of mutant libraries. The most commonly used method for DNA delivery into bacterial cells is chemical transformation which involves cell washes with $\mathrm{Mg}^{2+}$ and/or $\mathrm{Ca}^{2+}$ under ice-cold conditions followed by heat-shock treatment ${ }^{1-3}$. Despite the high efficiency of chemical transformation for delivering DNA into laboratory adapted Gram-negative bacteria, especially Escherichia coli K-12 strains, it has limited success with natural and pathogenic isolates ${ }^{4}$. For this reason, almost all DNA delivery approaches for pathogenic bacteria solely rely on electrotransformation which involves washing bacterial cells with $10 \%(\mathrm{v} / \mathrm{v})$ glycerol water followed by electro-permeabilisation at high voltages ${ }^{5,6}$. However, electrotransformation efficiency can remain low due to the presence of surface polysaccharides in some pathogenic bacteria, which act as a major barrier in successfully employing current DNA delivery methods ${ }^{7}$. In particular, high-efficiency transformation of Gram-negative pathogenic bacteria with either large DNA constructs $(>10 \mathrm{~kb})$ or with DNA-protein complexes (e.g. for transposon mutant library generation) remains a challenge that limits their wider application across strains and species.

The exact molecular mechanism of DNA passage through bacterial membranes is still incompletely understood, yet it has been suggested that both calcium heat-pulse induced transformation and electroporation likely involve DNA transport by disrupting membrane lipids which may form channels ${ }^{8,9}$. Yet the Polymyxin B nonapeptide (PMBN) which is a membrane lipid disturbing agent was previously 
reported to have no effect on $E$. coli K-12 transformation by the calcium heat-pulse method, except at high DNA concentrations $(\sim 1 \mathrm{mg} / \mathrm{ml})$ where it induced a small increase in transformation frequency ${ }^{10}$. PMBN is a cationic cyclic peptide that is devoid of the fatty acid tail of polymyxin $B$ and is not bactericidal ${ }^{11}$. PMBN was shown to increase the permeability of the outer membrane (OM) of certain Gram-negative bacteria (e.g. Salmonella enterica, and E. coli) towards hydrophobic antibiotics ${ }^{12}$, presumably via direct binding to lipid A components in the bacterial OM and disruption of the asymmetric lipid bilayer ${ }^{13,14}$. Despite these properties being known for over 30 years, PMBN has never been tested for its ability to enhance bacterial transformation by electroporation, the primary method used for efficient delivery of DNA into pathogenic bacteria. Here, we present an optimised protocol using PMBN for improved electrocompetency of pathogenic Gram-negative bacteria, including multidrug-resistant strains. Our method is unique in its use of PMBN to reversibly increase large plasmid delivery, mutagenesis by allelic exchange, and insertional mutant library construction in clinically relevant bacteria and could form the basis for the wider application of these methodologies across bacteria.

\section{Results}

\section{Growth of UPEC in the presence of PMBN increases electrotransformation efficiency}

To test whether PMBN could increase the electrotransformation frequency of non-K-12 pathogenic $E$. coli strains, we initially grew reference uropathogenic E. coli (UPEC) strain CFT073 in the presence or absence of PMBN and performed electroporation with standard cloning vector pSU2718. CFT073 is a reference pyelonephritis strain that despite being genetically malleable ${ }^{15,16}$ was previously reported to be relatively low-transformable 4 . Culturing CFT073 in the presence of PMBN drastically increased the number of recovered transformants $\sim 50$-fold (Figure 1a) with no noticeable impact on growth rate (data not shown). The electrotransformation increase by PMBN was dose dependent, with the highest frequency achieved after CFT073 treatment with $\geq 4 \mu \mathrm{g} / \mathrm{ml} \mathrm{PMBN}$ (Figure 1b). However, we noticed that the concentration of PMBN treatment negatively affected cell survival after electroporation, with less than $30 \%$ of cells treated with $4 \mu \mathrm{g} / \mathrm{ml}$ PMBN surviving post-electroporation (Figure 1c). Despite this marked decrease in cell survival, the transformation efficiency, which directly reflects the yield of transformants per DNA added, was still higher by $\sim 10$-fold when CFT073 cells were treated with PMBN at $4 \mu \mathrm{g} / \mathrm{ml}$ over untreated controls (Figure 1d). Culturing CFT073 in the presence of PMBN did not affect its chemical transformation frequency by the calcium heat-shock transformation method (Figure 1e), consistent with a previous report using other $E$. coli strains ${ }^{10}$.

In order to examine if the observed PMBN effects on CFT073 cells were permanent, we tested the electrotransformation frequency of bacterial cells grown in the presence of PMBN and then sub-cultured in the absence of PMBN prior to electroporation. In the absence of maintained growth in PMBN containing media, the electrotransformation frequency of CFT073 reverted to the lower frequency of the untreated control (Figure 1f). Brief exposure of CFT073 to PMBN was not sufficient to impart enhanced 
electrocompetency, with addition of PMBN for only 10 min of culture prior to harvesting the bacterial cells in fact reduced the electrotransformation frequency compared to untreated controls (Figure 1g). This suggests that bacterial growth in the presence of PMBN is required to achieve increased electrotransformation frequency, potentially implying that rearrangement of cellular components may be induced in response to PMBN.

Similar increases in electrotransformation frequency were observed for two other UPEC strains belonging to different $E$. coli lineages: reference cystitis isolate UTI89 and reference multi-drug resistant isolate EC958 (Figure $1 \mathrm{~h}$ and 1i, respectively). For all tested strains the PMBN-induced effects were dose dependent, with EC958 showing the highest increase ( 100-fold) in electrotransformation frequency over untreated controls. Taken together, our findings indicate that there is a threshold of electro-competency induced by PMBN for increased plasmid delivery and that an optimal PMBN concentration can be determined for different host strains to achieve the highest transformant yield.

\section{PMBN increases electrotransformation frequency of other Gram-negative bacteria}

To test the effects of PMBN on the electrotransformation frequency of other clinically relevant pathogens, we selected Salmonella enterica serovar Typhimurium strain SL1344 and Proteus mirabilis clinical isolate PM54 to culture in the presence of PMBN for electrotransformation with vector pSU2718. A dose dependent increase in SL1344 transformation frequency was observed with PMBN, with 100-fold more transformants obtained for PMBN treated cells at $4 \mu \mathrm{g} / \mathrm{ml}$ over untreated controls (Figure 2a). In contrast, the electrocompetency of $P$. mirabilis PM54 was unaffected by PMBN at all concentrations tested (Figure $2 b$ ). This finding is in agreement with a previous study reporting that binding of PMBN to $P$. mirabilis is inefficient. It is suggested that this is due to a less acidic LPS that confers on this species resistance to polycationic peptides ${ }^{13}$.

Electrotransformation frequency of $S$. Typhimurium SL1344 (a), and uropathogenic $P$. mirabilis strain PM54 (b) grown in different concentrations of PMBN. Data from three independent experiments are shown with bars denoting the group mean and error bars the standard error of the mean (mean \pm SEM).

\section{PMBN improves delivery of large plasmids into clinical isolates}

Investigation of virulence factors in pathogenic Gram-negative bacteria often requires construction of large plasmids containing entire gene operons that typically exceed $10 \mathrm{~kb}$, such as fimbrial and 0 antigen gene clusters ${ }^{17,18}$. Due mainly to their low transformation efficiency, these large constructs are typically studied in the highly transformable $E$. coli $\mathrm{K}-12$ background rather than the relevant (but also more technically challenging) background of the isolates that encode them. Therefore, we examined if PMBNgrown electrocompetent cells of UPEC strain CFT073 showed improved uptake of two previously constructed large constructs: pJRD215 ${ }^{19}(10.2 \mathrm{~kb})$ and pRMA154 $(22.5 \mathrm{~kb})^{18}$. The number of pJRD215 containing electrotransformants was more than 100-fold higher from PMBN treated cells over untreated 
controls (Figure 3a). For the larger pRMA154 construct, a small number of transformants was only obtained with PMBN-grown electrocompetent cells, while no colonies were recovered from CFT073 cells grown in the absence of PMBN (Figure 3a). These data demonstrate that PMBN can be employed to overcome the challenge of delivering large constructs into pathogenic strains.

\section{PMBN increases the yield of bacterial mutants obtained with the widely used lambda-Red recombineering system}

To date, most laboratories rely on allelic exchange mediated by $\lambda$-Red proteins as a common method to make chromosomal modifications in Gram-negative bacteria ${ }^{20}$. Typically, this method uses a host strain carrying a plasmid encoding the $\lambda$-Red recombination genes under an arabinose inducible promoter and electroporation of this host strain with a dsDNA PCR product carrying selection marker flanked by short homologous regions of target genes. Despite its success in recombineering DNA in laboratory $E$. coli strains, the success rate of genetic engineering in pathogenic strains is normally $>100$-fold lower due to their low transformability ${ }^{4}$ and strong efflux of arabinose via drug-efflux pumps expressed especially in multi-drug resistant pathogenic Salmonella strains ${ }^{21}$. Therefore, we tested if PMBN could improve the mutant yield of $\lambda$-Red recombination by mutating the oafA gene in reference $S$. Typhimurium strain SL1344 as an example. Using an optimised $\lambda$-Red mutagenesis protocol, we obtained a 5 -fold increase in the yield of putative $\triangle$ oafA:: cat mutant colonies when electro-competent cells were prepared by culture in media supplemented with $1 \mu \mathrm{g} / \mathrm{ml}$ PMBN (Figure $3 \mathrm{~b}$ ). PCR screening of 30 putative mutant colonies confirmed correct oafA deletion with $100 \%$ success rate in both groups (data not shown).

\section{PMBN increases the efficiency of constructing dense transposon mutant libraries}

Advances in next-generation genome sequencing technologies have allowed the development of Transposon Insertion Sequencing (TIS) as a powerful tool to screen for bacterial genes that are essential for cell survival and fitness under different conditions ${ }^{22}$. TIS library construction may involve electroporation of a protein-DNA complex, i.e. transposome, into bacterial cells that contains the transposase enzyme and transposon DNA encoding antibiotic resistance markers ${ }^{23}$. In order to generate a master library with adequate insertion density across the entire bacterial genome $e^{22}$, TIS-based methods require the pooling of multiple mutagenesis sub-libraries especially in pathogenic strains with low transformation frequency. As a result, the generation of dense transposon mutant libraries (ca. 100,000 mutants/Mb) across diverse bacteria and clinical isolates is often the limiting step in the wider application of TIS-based methodologies. Therefore, we tested if PMBN could enhance the delivery of protein-DNA complexes into a clinical UPEC strain to facilitate more efficient construction of dense TIS libraries. Intriguingly, we achieved an 8-fold increase in the insertional mutant yield of each electrotransformation reaction when UPEC strain UTI89 was grown in the presence of PMBN $(3 \mu \mathrm{g} / \mathrm{ml})$ (Figure 3c). These data suggest that PMBN can improve the delivery of DNA-protein complexes into pathogenic Gram-negative bacteria. 


\section{Discussion}

In this study we present an electrotransformation protocol optimised to enhance the electro-competency of clinically relevant Gram-negative bacteria using the cationic cyclic peptide PMBN. We showed that PMBN enhanced the electrotransformation frequency of several Gram-negative bacteria in a dose dependent manner, achieving improvement of up to 100 -fold. We also demonstrate how this protocol is readily applicable to enhance commonly used molecular biology methods involving DNA and DNAprotein complex delivery into bacterial cells.

The study of large genetic elements in bacteria (e.g. operons, genomic islands and virulence or antibiotic resistance plasmids) requires the successful delivery of large plasmid constructs in a clinically relevant host background and this still remains a challenge in the field. Cloning and introduction of such large constructs is relatively straightforward using laboratory K-12 E. coli or by a yeast assembly system ${ }^{24}$. However, the delivery of large constructs into most clinical strains can be a challenge, as demonstrated here. Conventionally triparental bacterial conjugation ${ }^{25}$ could be used, but this requires re-engineering of the host vector and is restricted to recipient strains that lack conjugation exclusion factors ${ }^{26,27}$. Here we have demonstrated successful delivery of a large plasmid construct $(25 \mathrm{~kb})$ encoding a gene cluster responsible for the synthesis of a heterologous $O$ antigen in a pathogenic $E$. coli background. We have also demonstrated a 5 -fold increase in the yield of chromosomal mutants in a widely studied pathogenic $S$. Typhimurium strain. The improvement in the mutagenesis rate we observed is likely attributed to two factors: a) enhanced DNA delivery into the cells, as demonstrated by our study findings and b) PMBN could also function as a membrane permeabilising agent to counteract TolC mediated efflux of Larabinose, thereby allowing more DNA template delivery as well as higher-level of induced expression of the lambda-Red proteins, resulting in an increased allelic exchange rate.

Our improved mutagenesis protocol using PMBN could also enable construction of chromosomal gene mutant libraries. This could be done by: 1 ) acquiring a target gene knockout with a positive-negative selection system ${ }^{28}$ by the standard lambda-Red mutagenesis method; 2) generating target gene templates with random mutations via error-prone PCR; 3 ) performing a second allelic exchange reaction using our PMBN enhanced mutagenesis protocol to deliver target gene DNA amplicons with random mutations; and 4) selecting putative flawless allelic mutants on an appropriate negative selection media. An improved yield of mutants by employing our PMBN method will enable efficient construction of a mutant gene library at the chromosomal level so that the study of the mutant alleles is not subject to plasmid copy number or expression differences. Lastly, we have shown that PMBN enhanced electrotransformation can be used to optimise the delivery of DNA-protein complexes (e.g. for TIS library construction) and we expect that this could also potentially be extended to developing a delivery system for ribonucleoprotein (RNP)-mediated CRISPR genome editing ${ }^{29}$ in bacterial cells for efficient targeted mutagenesis.

Interestingly, our findings with PMBN and pathogenic $E$. coli and $S$. Typhimurium strains, did not extend to a clinical $P$. mirabilis strain. $P$. mirabilis is naturally resistant to PMBN-induced antibiotic sensitising, in 
contrast to various $E$. coli and $S$. Typhimurium strains that were shown to be sensitised towards a set of antibiotics following treatment with $\mathrm{PMBN}^{12}$. PMBN was shown to readily bind to E. coli and Salmonella membranes at a level of 3-5 $\mu \mathrm{g} / \mathrm{mg}$ dry weight bacteria, whereas $P$. mirabilis membranes do not bind $\mathrm{PMBN}^{13}$. This would imply that the enhanced electrotransformation efficiency we observed requires PMBN to bind to the membrane and we thus predict that this protocol would have limitations with other naturally polymyxin-resistant bacteria such as Proteus vulgaris, Morganella morganii, Providencia stuartii and Serratia marcescens, but could be used to enhance electrotransformation frequency of polymyxin susceptible bacteria, such as Klebsiella pneumoniae, Klebsiella oxytoca, Enterobacter cloacae, Enterobacter agglomerans Acinetobacter calcoaceticus, Pseudomonas aeruginosa and Pseudomonas maltophilia ${ }^{12}$.

We also observed that growing pathogenic $E$. coli in the presence of PMBN made the electrocompetent cells more vulnerable to high voltage. We speculate that this is likely due to PMBN enhancing membrane damage induced by electroporation (thought to transitionally cause formation of aqueous pores on membranes and even membrane rupture ${ }^{30}$ ) by binding to lipid $A$ and disrupting the asymmetric bilayer of the bacterial OM. In future, the survival rate of PMBN-grown cells could be improved by exploring conditions that promote efficient repair of cell membrane damage in the cell. It is important to note however that the enhanced electrotransformation frequency by PMBN is likely not solely due to its membrane disrupting effects, as short exposure of bacterial cells to PMBN at early/mid-exponential phase instead reduced electrotransformation efficiency. This, combined with the fact that PMBN treatment had no effect on plasmid chemical transformation frequency shown here and previously ${ }^{10}$, while it increased the electrotransformation frequency of treated mid-exponential phase cells, suggests that bacterial growth in the presence of PMBN may be required to induce membrane modifications. Indeed, PMBN was previously reported to be sensed by the bacterial two component PhoPQ system ${ }^{31}$ and induce PmrAB-mediated gene expression ${ }^{32}$ to modify lipid $A$ in the $\mathrm{OM}$. Such modifications might be related to the enhanced electrotransformation frequencies we observed and a mechanistic investigation into PMBN-induced OM modifications constitutes a future investigation. Irrespective of the exact nature of the PMBN induced membrane changes, they seem to be transient and reversible as cells no longer exposed to PMBN revert to lower electrotransformation frequencies similar to PMBN untreated cells.

To our knowledge, this is the first study to show enhanced DNA delivery into clinically relevant Gramnegative bacteria using a cationic membrane binding peptide. The method presented here can be readily adapted for improving other genetic manipulation techniques involving the delivery of exogenous DNA into natural isolates. Therefore, we propose PMBN as a powerful Gram-negative membrane electropermeabilisation adjuvant for achieving enhanced DNA delivery into bacterial cells by electroporation.

\section{Materials And Methods}

\section{Bacterial strains and plasmids}


The bacterial strains and plasmids used in this work are listed in Table S1. Single colonies of bacterial strains grown overnight on Lennox Broth (LB) ${ }^{33}$ agar (1.5\% w/v) plates were picked and grown overnight in LB at $37^{\circ} \mathrm{C}$ for subsequent experiments. For Proteus mirabilis, modified plates with LB $3 \%(\mathrm{w} / \mathrm{v})$ agar and no $\mathrm{NaCl}$ were used to prevent swarming. Where appropriate, media were supplemented with ampicillin (Amp, $100 \mu \mathrm{g} / \mathrm{ml}$ ), kanamycin (Kan, $50 \mu \mathrm{g} / \mathrm{ml}$ ) or chloramphenicol (Chl, $25 \mu \mathrm{g} / \mathrm{ml}$ ).

\section{Preparation of electrocompetent cells and electroporation of plasmid DNA}

Bacterial cells grown overnight in $10 \mathrm{ml} \mathrm{LB}$ at $37^{\circ} \mathrm{C}$ were sub-cultured 1 in 100 into $10 \mathrm{ml} \mathrm{LB}$ supplemented with $1,2,4,6$, or $8 \mu \mathrm{g} / \mathrm{ml}$ of PMBN or stated in figure legends (prepared in $5 \mathrm{mg} / \mathrm{ml}$ in Milli $\mathrm{Q}$ water, Sigma, P2076) to mid-exponential phase (optical density at $600 \mathrm{~nm}\left(\mathrm{OD}_{600}\right)$ between 0.6-0.8). Bacterial cells were harvested via centrifugation $\left(5,000 \times \mathrm{g}, 5 \mathrm{~min}, 4^{\circ} \mathrm{C}\right)$, washed twice with $5 \mathrm{ml}$ of ice-cold $10 \%(\mathrm{v} / \mathrm{v})$ glycerol water and resuspended in $200 \mu \mathrm{l}$ ice-cold $10 \%(\mathrm{v} / \mathrm{v})$ glycerol water. Unless otherwise stated, $100 \mathrm{ng}$ of pSU2718 was used as a standard for all electrotransformation (quantity of all other plasmids used in this study was $100 \mathrm{ng}$ per electrotransformation; Table S1) was mixed with $100 \mu \mathrm{l}$ of competent cells and electroporated at $2.5 \mathrm{kV}$ in an electroporation cuvette with $2 \mathrm{~mm}$ gap. To determine the transient effect of PMBN on electrotransformation, mid-exponential cells grown in the presence of PMBN were then sub-cultured 1 in 100 into $10 \mathrm{ml}$ LB without PMBN and grow to mid-exponential phase for electroporation as described above. Electroporated cells were immediately recovered with $900 \mu \mathrm{l}$ of LB and incubated at $37^{\circ} \mathrm{C}$ with shaking $(200 \mathrm{rpm})$ for $45 \mathrm{~min}$ before spreading onto LB agar plates containing appropriate antibiotics. Recovery plates were incubated at $37^{\circ} \mathrm{C}$ for $16 \mathrm{~h}$. To determine viable cell numbers at different stages of the method, cultures were sampled immediately before and after electroporation and serial dilutions were plated on LB agar plates incubated overnight at $37^{\circ} \mathrm{C}$ to for enumeration of colony forming units (CFUs). Electrotransformation frequency was estimated as the number of transformants obtained per viable cells after electroporation. Transformation efficiency was defined as the number of transformants per $\mu \mathrm{g}$ of DNA.

\section{Preparation of chemically competent cells and chemical transformation of plasmid DNA}

Bacterial cells grown in $10 \mathrm{ml} \mathrm{LB}$ at $37^{\circ} \mathrm{C}$ were sub-cultured 1 in 100 into $10 \mathrm{ml} \mathrm{LB}$ with or without $6 \mu \mathrm{g} / \mathrm{ml}$ of PMBN and cultured to mid-exponential phase $\left(\mathrm{OD}_{600} \sim 0.6-0.8\right)$. Cells were harvested via centrifugation $(5,000 \times \mathrm{g}, 5 \mathrm{~min})$, sequentially washed and incubated on ice with $10 \mathrm{ml}$ of $100 \mathrm{mM} \mathrm{MgCl}$ for $1 \mathrm{~h}, 10 \mathrm{ml}$ of $100 \mathrm{mM} \mathrm{CaCl}_{2}$ for $1 \mathrm{~h}$, and finally resuspended into $0.3 \mathrm{ml}$ of $85 \mathrm{mM} \mathrm{CaCl}_{2}, 15 \%(\mathrm{v} / \mathrm{v})$ glycerol. For chemical transformation, $100 \mu \mathrm{l}$ of chemically competent cells were mixed with $100 \mathrm{ng}$ of pSU2718 plasmid DNA and incubated on ice for $20 \mathrm{~min}$, heat-shocked at $42^{\circ} \mathrm{C}$ for $30 \mathrm{sec}$ and rested on ice for 5 min. $900 \mu$ l of LB was then added and transformed cells were incubated at $37^{\circ} \mathrm{C}$ with aeration $(200 \mathrm{rpm})$ for 45 min before spreading $(100 \mu l)$ onto LB agar plates containing appropriate antibiotics.

Transformation frequency was determined as above.

\section{Bacterial mutagenesis via allelic exchange}


Mutagenesis was performed as described previously 20,34 with laboratory adapted optimisations. Briefly Salmonella enterica serovar Typhimurium strain SL1344 harbouring plasmid pKD46 grown overnight in $10 \mathrm{ml} \mathrm{LB}$ at $30^{\circ} \mathrm{C}$ was sub-cultured into $25 \mathrm{ml}$ LB in a $250 \mathrm{ml}$ flask supplemented with or without $1 \mu \mathrm{g} / \mathrm{ml}$ of PMBN. Expression of the lambda phage-derived Red proteins were then induced with $50 \mathrm{mM} \mathrm{L-}$ arabinose at $\mathrm{OD}_{600}$ of 0.3 . Bacterial cells were then harvested at $\mathrm{OD}_{600}$ of $0.6-0.8$ by directly mixing 15 $\mathrm{mL}$ cultures with $20 \mathrm{ml}$ of $10 \%(\mathrm{v} / \mathrm{v})$ ice-cold glycerol water followed by centrifugation. Bacterial cells equivalent to $\mathrm{OD}_{600}$ of 2 in $1 \mathrm{ml}$ were then taken and washed twice with $10 \%(\mathrm{v} / \mathrm{v})$ ice-cold glycerol and finally resuspended in $100 \mu \mathrm{l}$ of $10 \%(\mathrm{v} / \mathrm{v})$ ice-cold glycerol for subsequent electroporation. The cat gene was PCR amplified from pKD3 using Taq DNA Polymerase with ThermoPolß Buffer (New England BioLabs, M0267) following the manufacturer's protocol and primers containing 50 bp up- and downstream sequences homologous to the oaf target gene (Table S1). The amplicon was then treated with Dpnl (New England BioLabs, R0176) at $37^{\circ} \mathrm{C}$ for $1 \mathrm{~h}$, purified using QIAquick PCR Purification Kit (Qiagen, 28104) and quantified by NanoPhotometer ${ }^{\circledR}$ N60/N50 (IMPLEN).

Purified PCR amplicon $(1.5 \mu \mathrm{g})$ was then introduced into electrocompetent cells via electroporation as above and cells were immediately recovered in $3 \mathrm{ml} \mathrm{LB}$ in a $50 \mathrm{ml}$ Falcon tube that was incubated for $2 \mathrm{~h}$ at $37^{\circ} \mathrm{C}$ before plating out $(100 \mu \mathrm{l})$ on LB agar plates supplemented with $17 \mu \mathrm{g} / \mathrm{ml}$ chloramphenicol. Plates were incubated at $37^{\circ} \mathrm{C}$ for $16 \mathrm{~h}$ to acquire chloramphenicol resistant colonies. Samples $(10 \mu \mathrm{l})$ immediately before and after electroporation were serially diluted and spot plated onto LB agar plates, incubated at $37^{\circ} \mathrm{C}$ overnight to determine viable cells. Candidate mutant colonies were picked and patched onto LB agar supplemented with chloramphenicol, and cell lysates were prepared in $100 \mu$ water by heating to $100^{\circ} \mathrm{C}$ for $5 \mathrm{~min}$. Lysate DNA was screened by PCR using primers annealing to regions flanking the amplicon insertion site (Table S1).

\section{Transposon Insertion Sequencing (TIS) library construction}

TIS library construction was done as previously described ${ }^{22}$. Briefly, a single colony of UPEC strain UTI89 was inoculated in $5 \mathrm{ml}$ of LB broth and grown overnight at $37^{\circ} \mathrm{C}$ shaking at $180 \mathrm{rpm}$. The overnight was used to inoculated into $15 \mathrm{ml}$ of $2 x$ TY medium (1:100) and grown at $37^{\circ} \mathrm{C}$ in the absence or presence of $3 \mu \mathrm{g} / \mathrm{ml}$ PMBN shaking at $180 \mathrm{rpm}$ until the culture reached an $\mathrm{OD}_{600}$ between $0.65-0.78$. Culture volume equivalent to $\mathrm{OD}_{600}$ of $5 \mathrm{in} 1 \mathrm{ml}$ was collected and the cells were then harvested by centrifugation at 2410 $\mathrm{x}$ g. The cell pellet was washed with twice equal culture volume of $10 \%(\mathrm{v} / \mathrm{v})$ ice cold glycerol twice at $2410 \times \mathrm{g}$ at $4^{\circ} \mathrm{C}$, and then resuspended in $100 \mu \mathrm{l}$ of $10 \%(\mathrm{v} / \mathrm{v})$ glycerol to prepare electrocompetent cells. The UTI89 electrocompetent cells were then incubated briefly with $0.2 \mu \mathrm{l}$ of Kan2-Tn5-mini transposome (Lucigen, TSM99K2) and electroporated using a $2 \mathrm{~mm}$ gapped cuvette using $2.5 \mathrm{kV}$ of voltage. After electroporation, the cells were recovered by adding $900 \mu \mathrm{l}$ of $37^{\circ} \mathrm{C}$ pre-warmed SOC medium ${ }^{1}$ and incubating for 2 hours at $37^{\circ} \mathrm{C}$ with shaking at $180 \mathrm{rpm}$. Serial dilutions were prepared from the electroporated samples before and after recovery and plated on LB plates with no antibiotics and on 35 $\mu \mathrm{g} / \mathrm{ml}$ Kanamycin containing LB plates, respectively.

\section{Declarations}




\section{Acknowledgement}

This work was supported in part by Australian National Health and Medical Research Council Project Grant (GNT1144046), a Clive and Vera Ramaciotti Health Investment Grant (2017HIG0119) and a Georgina Sweet Award for Women in Quantitative Biomedical Science to MT.

\section{Author contributions}

JQ, YH and MT contributed to project conception and design; JQ, YH and KP conducted experiments, and contributed to data collection, analysis and interpretation; IRH and MT supervised the study, contributed to data interpretation and obtained the funding. RM contributed to data interpretation and provided study reagents. JQ and MT drafted and substantially revised the manuscript. All authors edited the manuscript.

\section{Additional Information}

The authors declare no competing interests.

\section{References}

1. Hanahan, D. Studies on transformation of Escherichia coli with plasmids. J Mol Bio/ 166, 557-580, doi:10.1016/s0022-2836(83)80284-8 (1983).

2. Mandel, M. \& Higa, A. Calcium-dependent bacteriophage DNA infection. J Mol Biol 53, 159-162, doi:10.1016/0022-2836(70)90051-3 (1970).

3. Dagert, M. \& Ehrlich, S. D. Prolonged incubation in calcium chloride improves the competence of Escherichia coli cells. Gene 6, 23-28, doi:10.1016/0378-1119(79)90082-9 (1979).

4. Lee, D. J. et al. Gene doctoring: a method for recombineering in laboratory and pathogenic Escherichia coli strains. BMC Microbio/ 9, 252, doi:10.1186/1471-2180-9-252 (2009).

5. Harlander, S. K. \& McKay, L. L. Transformation of Streptococcus sanguis Challis with Streptococcus lactis plasmid DNA. Appl Environ Microbio/ 48, 342-346, doi:10.1128/aem.48.2.342-346.1984 (1984).

6. Dower, W. J. Electroporation of bacteria: a general approach to genetic transformation. Genet Eng ( $N$ Y) 12, 275-295, doi:10.1007/978-1-4613-0641-2_14 (1990).

7. Regué, M., Enfedaque, J., Camprubi, S. \& Tomás, J. M. The O-antigen lipopolysaccharide is the major barrier to plasmid DNA uptake by Klebsiella pneumoniae during transformation by electroporation and osmotic shock. Journal of Microbiological Methods 15, 129-134, doi:https://doi.org/10.1016/0167-7012(92)90077-H (1992).

8. Sugar, I. P., Forster, W. \& Neumann, E. Model of cell electrofusion. Membrane electroporation, pore coalescence and percolation. Biophys Chem 26, 321-335, doi:10.1016/0301-4622(87)80033-9 (1987). 
9. Nikaido, H. \& Vaara, M. Molecular basis of bacterial outer membrane permeability. Microbiological reviews 49, 1-32, doi:10.1128/mr.49.1.1-32.1985 (1985).

10. Viljanen, $P$. The effect of polymyxin B nonapeptide (PMBN) on transformation. Biochem Biophys Res Commun 143, 923-927, doi:10.1016/0006-291x(87)90338-x (1987).

11. Vaara, M., Viljanen, P., Vaara, T. \& Makela, P. H. An outer membrane-disorganizing peptide PMBN sensitizes E. coli strains to serum bactericidal action. J Immunol 132, 2582-2589 (1984).

12. Viljanen, P. \& Vaara, M. Susceptibility of gram-negative bacteria to polymyxin B nonapeptide. Antimicrob Agents Chemother 25, 701-705, doi:10.1128/AAC.25.6.701 (1984).

13. Vaara, M. \& Viljanen, P. Binding of polymyxin B nonapeptide to gram-negative bacteria. Antimicrob Agents Chemother 27, 548-554, doi:10.1128/AAC.27.4.548 (1985).

14. Moore, R. A., Bates, N. C. \& Hancock, R. E. Interaction of polycationic antibiotics with Pseudomonas aeruginosa lipopolysaccharide and lipid A studied by using dansyl-polymyxin. Antimicrob Agents Chemother 29, 496-500, doi:10.1128/AAC.29.3.496 (1986).

15. Buckles, E. L. et al. Identification and characterization of a novel uropathogenic Escherichia coliassociated fimbrial gene cluster. Infect Immun 72, 3890-3901, doi:10.1128/IAI.72.7.3890-3901.2004 (2004).

16. Totsika, M., Heras, B., Wurpel, D. J. \& Schembri, M. A. Characterization of two homologous disulfide bond systems involved in virulence factor biogenesis in uropathogenic Escherichia coli CFT073. $J$ Bacterio/ 191, 3901-3908, doi:10.1128/JB.00143-09 (2009).

17. Klemm, P., Jorgensen, B. J., van Die, I., de Ree, H. \& Bergmans, H. The fim genes responsible for synthesis of type 1 fimbriae in Escherichia coli, cloning and genetic organization. Mol Gen Genet 199, 410-414, doi:10.1007/BF00330751 (1985).

18. Morona, R., Mavris, M., Fallarino, A. \& Manning, P. A. Characterization of the rfc region of Shigella flexneri. J Bacterio/ 176, 733-747, doi:10.1128/jb.176.3.733-747.1994 (1994).

19. Davison, J., Heusterspreute, M., Chevalier, N., Ha-Thi, V. \& Brunel, F. Vectors with restriction site banks. V. pJRD215, a wide-host-range cosmid vector with multiple cloning sites. Gene 51, 275-280, doi:10.1016/0378-1119(87)90316-7 (1987).

20. Datsenko, K. A. \& Wanner, B. L. One-step inactivation of chromosomal genes in Escherichia coli K-12 using PCR products. Proc Natl Acad Sci U S A. 97, 6640-6645, doi:D - NLM: PMC18686 EDAT2000/06/01 09:00 MHDA- 2000/07/15 11:00 CRDT- 2000/06/01 09:00 AID 10.1073/pnas.120163297 [doi] AID - 120163297 [pii] PST - ppublish (2000).

21. Liao, S. W. et al. Effects of L-arabinose efflux on lambda Red recombination-mediated gene knockout in multiple-antimicrobial-resistant Salmonella enterica serovar Choleraesuis. Arch Microbio/ 200, 219-225, doi:10.1007/s00203-017-1436-4 (2018).

22. Goodall, E. C. A. et al. The Essential Genome of Escherichia coli K-12. Mbio 9, doi:10.1128/mBio.02096-17 (2018).

23. Goryshin, I. Y., Jendrisak, J., Hoffman, L. M., Meis, R. \& Reznikoff, W. S. Insertional transposon mutagenesis by electroporation of released Tn5 transposition complexes. Nat Biotechnol 18, 97- 
100, doi:10.1038/72017 (2000).

24. Liu, M. A., Kenyon, J. J., Lee, J. \& Reeves, P. R. Rapid customised operon assembly by yeast recombinational cloning. App/ Microbiol Biotechnol 101, 4569-4580, doi:10.1007/s00253-017-82139 (2017).

25. Fischer-Fantuzzi, L. \& Di Girolamo, M. Triparental matings in Escherichia coli. Genetics 46, 13051315, doi:10.1093/genetics/46.10.1305 (1961).

26. Achtman, M., Kennedy, N. \& Skurray, R. Cell--cell interactions in conjugating Escherichia coli: role of traT protein in surface exclusion. Proceedings of the National Academy of Sciences of the United States of America 74, 5104-5108, doi:10.1073/pnas.74.11.5104 (1977).

27. Achtman, M., Manning, P. A., Edelbluth, C. \& Herrlich, P. Export without proteolytic processing of inner and outer membrane proteins encoded by $\mathrm{F}$ sex factor tra cistrons in Escherichia coli minicells. Proceedings of the National Academy of Sciences of the United States of America 76, 4837-4841, doi:10.1073/pnas.76.10.4837 (1979).

28. Khetrapal, V. et al. A set of powerful negative selection systems for unmodified Enterobacteriaceae. Nucleic acids research 43, e83, doi:10.1093/nar/gkv248 (2015).

29. O'Keeffe Ahern, J. et al. Non-viral delivery of CRISPR-Cas9 complexes for targeted gene editing via a polymer delivery system. Gene Ther, doi:10.1038/s41434-021-00282-6 (2021).

30. Weaver, J. C. Electroporation theory. Concepts and mechanisms. Methods Mol Biol 55, 3-28, doi:10.1385/0-89603-328-7:3 (1995).

31. Murata, T., Tseng, W., Guina, T., Miller, S. I. \& Nikaido, H. PhoPQ-mediated regulation produces a more robust permeability barrier in the outer membrane of Salmonella enterica serovar typhimurium. $J$ Bacteriol 189, 7213-7222, doi:10.1128/JB.00973-07 (2007).

32. Richards, S. M., Strandberg, K. L., Conroy, M. \& Gunn, J. S. Cationic antimicrobial peptides serve as activation signals for the Salmonella Typhimurium PhoPQ and PmrAB regulons in vitro and in vivo. Front Cell Infect Mi 2, 102, doi:10.3389/fcimb.2012.00102 (2012).

33. Lennox, E. S. Transduction of linked genetic characters of the host by bacteriophage P1. Virology 1, 190-206, doi:10.1016/0042-6822(55)90016-7 (1955).

34. Qin, J., Doyle, M. T., Tran, E. N. H. \& Morona, R. The virulence domain of Shigella IcsA contains a subregion with specific host cell adhesion function. PloS one 15, e0227425, doi:10.1371/journal.pone.0227425 (2020).

\section{Figures}


a

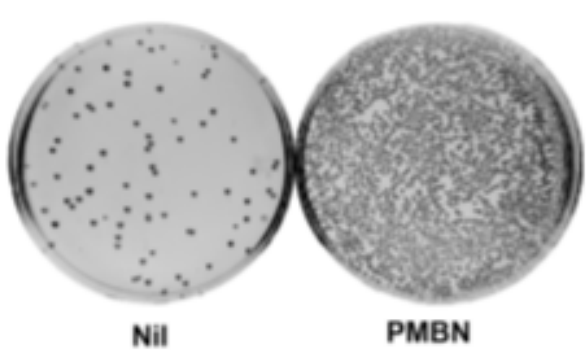

Nil b

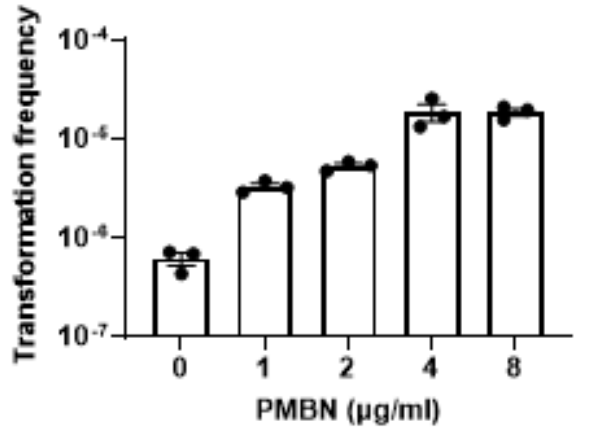

e

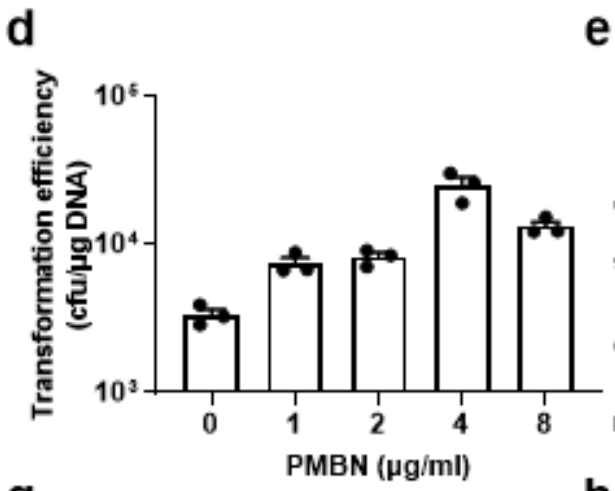

g

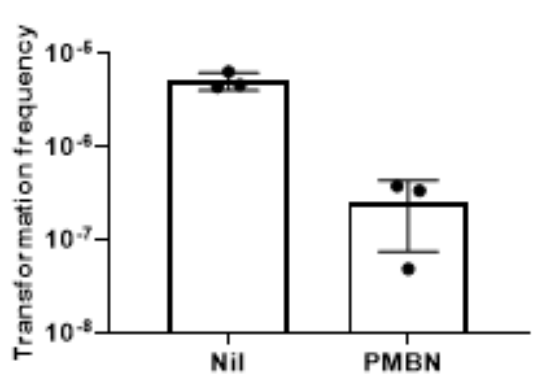

h

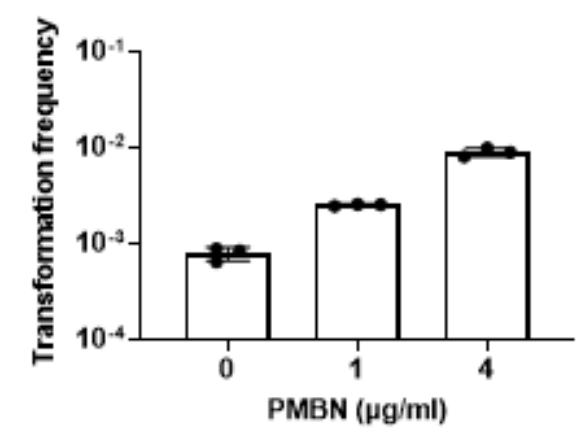

C

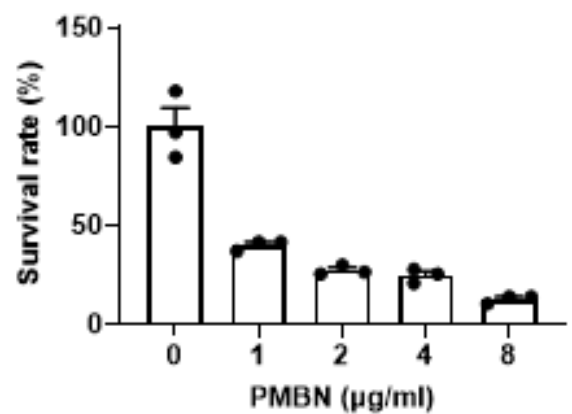

f

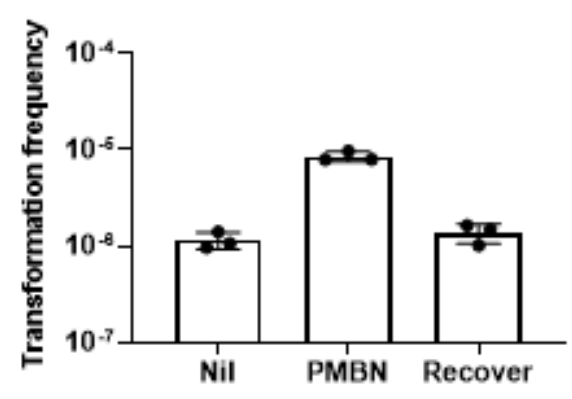

i

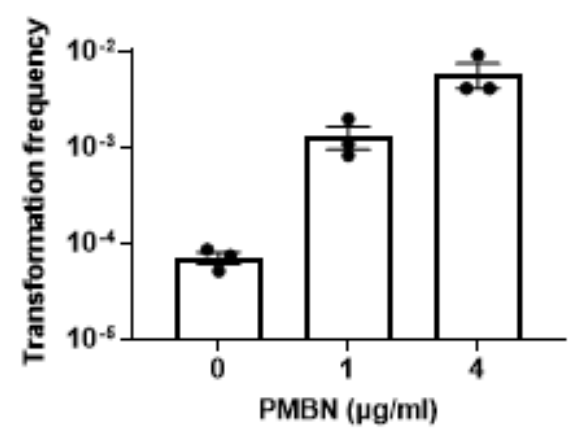

Figure 1

UPEC growth in the presence of PMBN increases cell electrocompetency in a reversible and dose dependent manner. (a) Representative plate images comparing the yield of pSU2718 plasmid electrotransformants of UPEC strain CFT073 grown without (Nil) or with PMBN $(6 \mu \mathrm{g} / \mathrm{ml})$ prior to electroporation. (b) Transformation frequency, (c) survival rate after electroporation, and (d) transformation efficiency of CFT073 grown with different concentrations of PMBN. (e) Chemical transformation frequency of CFT073 grown in the absence (Nil) or presence of PMBN $(6 \mu \mathrm{g} / \mathrm{ml})$. (f) Electrotransformation frequency of CFT073 grown in the presence of PMBN $(4 \mu \mathrm{g} / \mathrm{ml})$ and then subcultured into media devoid of PMBN prior to electroporation (Recover). (g) Electrotransformation frequency of CFT073 grown to $\mathrm{OD}_{600} \sim 0.7$ and subsequently incubated without (Nil) or with PMBN (1 $\mu \mathrm{g} / \mathrm{ml}$ ) for $10 \mathrm{~min}$ before harvesting and electroporation. Electrotransformation frequency of UPEC strains UTI89 (h) and EC958 (i) grown without or with different concentrations of PMBN. Data from three 
independent experiments are shown with bars denoting the group mean and error bars the standard error of the mean (mean \pm SEM).

a

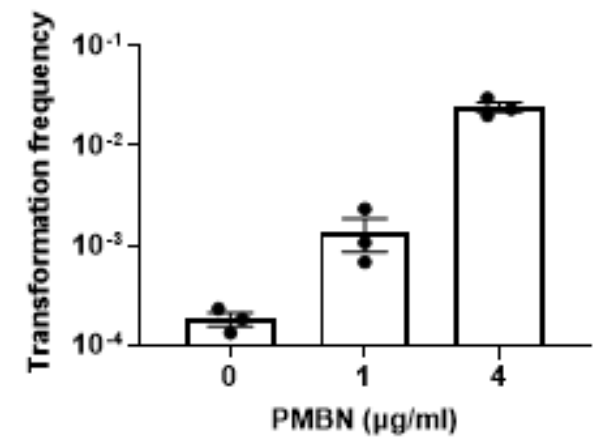

b

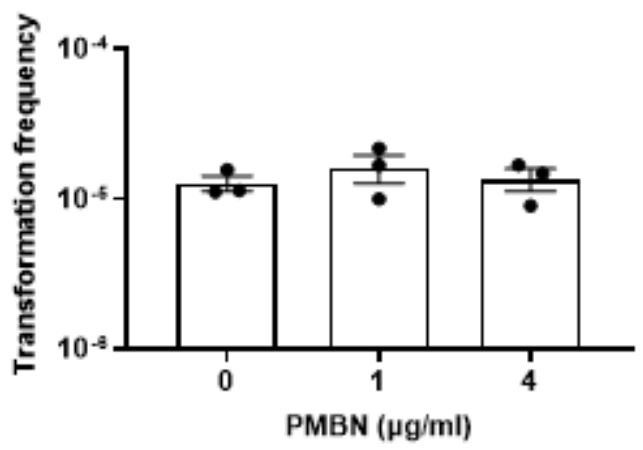

Figure 2

PMBN-mediated effects on electrotransformation frequency of $S$. Typhimurium and $P$. mirabilis.

Electrotransformation frequency of $S$. Typhimurium SL1344 (a), and uropathogenic $P$. mirabilis strain PM54 (b) grown in different concentrations of PMBN. Data from three independent experiments are shown with bars denoting the group mean and error bars the standard error of the mean (mean \pm SEM).

a

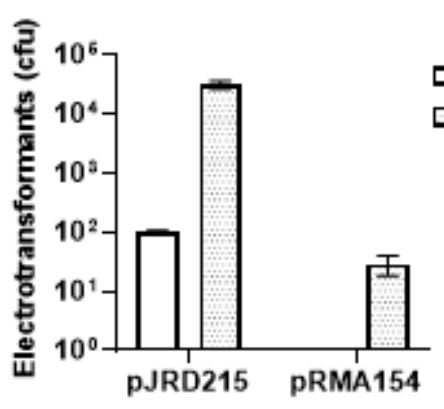

b

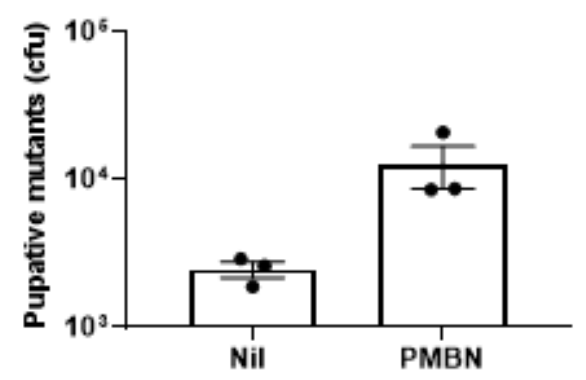

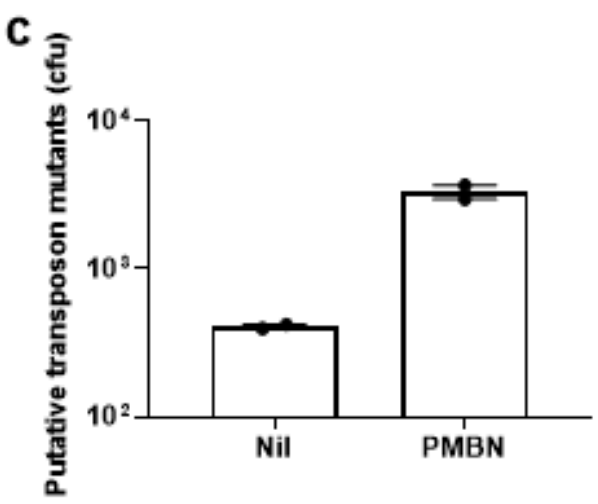

Figure 3

Application of the PMBN electroporation method to improving delivery of large size DNA, mutagenesis rates and TIS library yields in Gram-negative clinical isolates. (a). Number of UPEC CFT073

electrotransformants with large plasmid constructs recovered from cultures prepared without (Nil) or with PMBN $(1 \mu \mathrm{g} / \mathrm{ml})$. (b) Comparison of putative $\triangle$ oafA::cat mutant colony yields following $\lambda$-Red mutagenesis of $S$. Typhimurium SL1344 electrocompetent cells without (Nil) or with $1 \mu \mathrm{g} / \mathrm{ml}$ PMBN. (c) Comparison of putative transposon mutant yields in UPEC UTI89 following standard electroporation 
without PMBN (Nil) or with PMBN (3 $\mathrm{gg} / \mathrm{ml})$ treatment. Data from three (a\&b) or two (c) independent experiments are summarised in graphs showing mean \pm SEM.

\section{Supplementary Files}

This is a list of supplementary files associated with this preprint. Click to download.

- TableS1.docx 